\title{
A dimensão performativa do gesto na prática docente ${ }^{*}$
}

\author{
Marcelo de Andrade Pereira \\ Universidade Federal de Santa Maria, Departamento de Fundamentos da Educação
}

O presente estudo, de caráter ensaístico, trata da dimensão performativa do gesto na prática docente, desde um ponto de vista filosófico. Para tanto, discorre sobre o sentido do gesto em geral e na prática educativa. A análise procede da diferenciação do sentido do gesto - do mero gesto motor em relação ao gesto figurado ou expressivo - a partir da qual se depreende a acepção própria de gesto à investigação. Infere-se que a dimensão performativa e, portanto, expressiva do gesto permite criar um espaço de experimentação e construção do saber qualitativamente distinto do ordinário, não regulado por fins de ordem meramente biológica, cognitiva ou instrumental. Essa perspectiva compreende o gesto desde sua dimensão performativa como ato estético. Pretende-se descrever e analisar os conteúdos, os objetos, as condições e os efeitos do elemento estético (do ato e da experiência estética propriamente dita) perante uma prática docente performativa. Este texto reflete, ainda, sobre a materialidade do conhecimento docente. A investigação é amparada pelas intuições de

${ }^{*}$ Esse texto foi apresentado na $33^{\mathrm{a}}$ Reunião Anual da ANPEd no GT 24 - Educação e Arte.
Walter Benjamin, Osman Lins, Hans Ulrich Gumbrecht, Jean Galard, Baldine Saint Girons, Jacques Rancière, Paul Zumthor e Marcel Jousse.

Os rumores da chuva refluíram, levando a paisagem; quando tornaram, vieram sós, desencantados. $\mathrm{O}$ velho André abriu os olhos. Mariana estava de costas para a janela, os cotovelos no peitoril e as mãos cruzadas sobre o ventre. Por trás dela na linha exterior das fasquias, cintilavam gotas de água; cresciam trêmulas, deslizavam, uniam-se, caíam. Uma claridade opalina subia do pescoço, tocava o queixo da moça, banhava sua face direita e extinguia-se na penugem da fonte. $\mathrm{O}$ resto das feições, mal se percebia; mas era evidente que algo se anunciava, um evento único, secreto - e ele conteve a respiração. A parte do colo sobre que incidia a luz pálida fremiu, palpitou, os lábios se entreabriram, estremeceram as narinas. Soprou um vento forte, que agitou seus cabelos e precipitou o tombar das gotas de água. Ela moveu a cabeça em direção à luz, lenta, com um suspiro ansioso. O rosto era belo e se renovava, como um ser adormecido que enriquecesse no deslumbramento de um sonho. O pai não se enganara, aquele era um momento único, ele cruzava um limite: quando se afastasse, os últimos gestos da infância estariam mortos. Isto 
é inexprimível - pensou. E que não o é? Meus gestos de hoje talvez não sejam menos expressivos que minhas palavras de antes. Fechou os olhos, para conservar durante o maior tempo possível aquela visão. Quando tornou a abri-los, Mariana se fôra, a chuva passara e ele viu que estivera dormindo, sem haver sonhado. (Lins, 2003, p. 37-38)

"Meus gestos de hoje talvez não sejam menos expressivos que minhas palavras de antes". Nesse enunciado de André, protagonista do conto Os Gestos, de Osman Lins, apresenta-se uma tomada de consciência da natureza expressiva do gesto, de sua significação, intensidade e amplitude. Embora a maior parte do relato descreva um gesto alheio ao personagem central - gesto que marca de maneira sutil e delicada a passagem da infância à adolescência de um de seus rebentos -, é a um gesto ou a um conjunto de gestos anteriores que o enunciado se refere. Anarrativa de Osman Lins começa, com efeito, pela descrição implícita das condições precárias de saúde e afasia de André. Durante um dia, acompanhamos a imobilidade e a indignação de um homem que perdeu a capacidade, segundo ele, de se expressar. André vocifera com o corpo, gesticula de maneira febril e impaciente. Pensa-se para sempre exilado. Diz ele no começo da narrativa: "Minhas palavras morreram, só os gestos sobrevivem. [...] Só os gestos, pobres gestos." (idem, p. 31). A percepção da sobrevivência do gesto, por parte de André, não é indício, ao menos não naquele momento, de que o gesto possa de fato exprimir algo. O gesto é pobre, muito pobre, infere. Nessa passagem do texto, aventa-se um sentido de gesto desprovido de expressividade, meramente indicativo, mecânico, funcional. Essa intuição por certo se modifica quando o personagem acaba de maneira desinteressada sendo "iluminado", "atravessado" pelas refulgências do gesto alheio - eis o que trata o longo excerto do texto apresentado. $\mathrm{O}$ personagem vê, ao fim e ao cabo, no gesto do outro a si, os seus; vê que o gesto "fala" tanto ou mais que a palavra.

\section{II}

André viu: o gesto está prenhe de significação; o gesto gesta uma pletora de sentidos, dados (pela sen- sação, como materialidade) e produzidos (pelo signo). De um entendimento de gesto meramente motor - significado em parte por códigos de ordem sócio-histórica e cultural, o personagem passou a tomar, porquanto o tenha testificado, o gesto como uma forma-força expressiva. A intensidade dessa experiência, da beleza do gesto, transposta na narrativa na forma de um sentimento de encantamento, plenitude e serenidade, reforça a hipótese de que a experiência estética produzida, disparada pelo gesto - compreendido como ato estético -, faz ver de maneira mais clara, luminosa e distinta o real [simbolizado e imaginado] que se lhe impõe. O entendimento de que o gesto constitua [como ato estético] uma ação simbólica de efeito estético por natureza infinitamente variada - transfere ao gesto uma pluralidade de sentidos possíveis, plenos, intensos, consistentes (Galard, 2008, p. 52-53).

Este estudo, não obstante, compartilha com André - e Osman Lins e Jean Galard e tantos outros - tais intuições, a saber: que o gesto permite redimensionar o sentido e a função do ato, das ações, das condutas humanas diante da simbolização dos modos de ser, de identificar-se, de conduzir-se perante o outro; de adotar, enfim, uma arte que avalie, retrabalhe e recomponha a ação humana como gesto (idem, p. 20), que a torne plenamente consciente e responsável por seus efeitos - sejam eles previstos, imprevistos ou não previsíveis.

No âmbito da educação, para o qual se dirige o presente ensaio, a investigação sobre o sentido do gesto - sua natureza, função e efeito - concerne, de fato, ao problema da comunicação docente. Em outras palavras, responde à redução do espectro de significação, amplitude e intensidade da linguagem [em geral] em prol de uma transmissão clara e distinta, sem ruídos ou margens, na prática educativa; ao automatismo da linguagem verbal e não verbal no processo de ensino e aprendizagem - isto é, à mecanização do falar e do agir docentes; à reiteração do mesmo, do dado em detrimento do diferente e do possível; à incompatibilidade entre os modos de abordagem do real e o real propriamente dito - ou seja, ao engessamento das formas de apreensão e construção da realidade; formas que 
se antepõem e, por conseguinte, a sobredeterminam; formas de transmissão sobremaneira midiatizadas. Essas intuições decorrem por certo da especulação de Walter Benjamin acerca da transformação de formas narrativas e da consequente modificação da faculdade da percepção à época do capitalismo tardio (Benjamin, 1989, 1994).

Seja como for, a reflexão em torno do elemento estético - compreendido nesta investigação na pergunta pela dimensão performativa do gesto, pelo ato estético e pela experiência estética - permite postular uma educação de ato - como atualização de potência, para recobrarmos o sentido cunhado por Aristóteles do termo -, uma educação atualizadora não orientada por princípios meramente utilitários, técnico-instrumentais - signos de uma educação moderna, reducionista, estabilizadora e reprodutora de sentidos (sensações, significados, finalidades) - redentores e/ou pequenoburgueses; permite postular uma educação que não prejulga de funções, que não se reduz a um exercício infértil e retentivo de descrição-prescrição do real, de emudecimento do real. A educação de ato - que passa, como veremos, pelo gesto - é, com efeito e por efeito, estética. O sentido do performativo - manifesto numa dada acepção de gesto - remonta precisamente a essa noção e propriedade de realização, de atualização do possível; refere como ato e experiência estéticos a captação de um fluxo interminável e imponderável de sentidos, de [re]construção de sentidos, dados e produzidos, de pensamento e de experiência (Santos, 2003).

A contraparte real aplicada dessa discussão, relativamente imprecisa e/ou não explorada, indaga sobre a consistência formal dos princípios que regulam não apenas nossa prática educativa, mas, de uma maneira geral, sobre a nossa conduta, a nossa ação, sobre o nosso modo de nos dirigir, de nos colocar perante o outro, de agir com o outro - leia-se, de "falar" para o outro, de ser ouvido, escutado por ele, de nos fazer entender pelo outro. Para tanto, concorre o gesto, termo que outrora definia, tal como observa Walter Benjamin (1994, p. 220), uma prática formativa, de transmissão, quase artística, artesanal, de compartilhamento de sen- tidos. O exame da dimensão performativa do gesto na prática docente permite, pois, identificar os termos da ação educativa nos quais conflui à ética uma estética. Impõe-se, pois, como uma discussão sobre a estética da conduta ou arte do comportamento docente - isto é, a arte de "saber encontrar o gesto adequado [mesmo que inadequado, ruidoso e/ou marginal], no momento oportuno" (Galard, 2008, p. 19).

\section{III}

Gesto: "gesticular [...]; movimento do corpo, voluntário ou involuntário, que revela estado psicológico ou intenção de exprimir ou realizar algo [...]; expressão singular, aparência, aspecto, fisionomia; [...] maneira de se manifestar, atitude, ação" (Houaiss, 2003, p. 1449). As acepções de gesto arroladas pelo célebre dicionário de língua portuguesa Houaiss, embora satisfatórias, carecem de precisão e complexidade. De natureza motriz, o gesto refere todos os movimentos corporais que constituem [ou se constituem como] uma forma de expressão, que compõem e definem a especificidade do humano da ação (Jousse, 2008, p. 687). ${ }^{1}$ Todavia, o gesto difere do ato, por efeito e finalidade. Vejamos. No entendimento de Jean Galard (2008, p. 27), o ato é uma "ação" não descrita. O gesto, em contrapartida, apresenta-se como ato que desperta a atenção - inclusive em relação ao modo como se apresenta. "O gesto é o ato considerado na totalidade de seu desenrolar, percebido enquanto tal, observado, captado. O ato é o que resta de um gesto cujos momentos foram esquecidos e do qual só se conhecem seus resultados" (idem, ibidem). Se o gesto expressa, realiza, o ato comunica, informa.

O gesto é um dispositivo, um aparelho de registro e de amplificação do sentido na ação. Ora reforça,

\footnotetext{
${ }^{1}$ Uma investigação mais precisa acerca do caráter natural do
} gesto é desenvolvida na obra socioestética de André Leroi-Gourhan intitulada Le geste et la parole: technique et langage (2008). Nessa obra, o antropólogo Leroi-Gourhan apresenta um histórico de desenvolvimento do comportamento material do homem; realiza, por assim dizer, uma paleontologia da linguagem. 
ora atenua o que é dito, ora compensa, ora substitui um enunciado por força de sua diluição em um outro plano expressivo - nisso consiste, como vimos, a diferença funcional do gesto em relação ao ato. "Visíveis ou invisíveis, macroscópicos ou microscópicos, [...] conscientes ou inconscientes, voluntários ou involuntários", os gestos aduzem, invariavelmente, a uma ação radicada no corpo (Jousse, 2008, p. 687). Como linguagem, o gesto refere um sistema expressivo plástico, concreto e objetivo; um sistema estético, de princípios constantemente ativos, ainda que não necessariamente formulados (Galard, 2008, p. 22).

Nesse sentido, ele, o gesto, responde ao paulatino distanciamento entre a experiência e sua representação na linguagem, entre representação material e representação conceitual; responde a um processo histórico de desmaterialização do mundo, de modernização dos sentidos. $^{2} \mathrm{O}$ gesto confere ao real do conceito sua

2 A modernização dos sentidos designa, grosso modo, o processo histórico de mutação da sensibilidade - em especial da faculdade perceptiva - no Ocidente, por força da supressão paradigmática moderna dos pressupostos metafísicos acerca do conhecimento. Caracteriza-se por uma espécie de distanciamento do sujeito em relação à dimensão da presença, da matéria, ante a afirmação de um modelo de conhecimento representacional. Hans Ulrich Gumbrecht, na obra homônima A modernização dos sentidos, de 1998, discorre sobre o desenvolvimento de tal processo desde o ponto de vista da arte e da literatura - visto supor que essas formas cristalizam modos de ser, sentir e pensar histórica e culturalmente situados. Uma especulação semelhante a de Gumbrecht pode ser encontrada em Walter Benjamin. No ensaio intitulado Sobre alguns temas em Baudelaire (1989), Benjamin aponta para a dificuldade de recepção da poesia lírica em meados do século XIX, dificuldade esta que seria, segundo ele, causada por uma espécie de desnível entre a experiência poética e a experiência do leitor. Todavia, o que Benjamin coloca não é - como poderia parecer - uma discussão acerca do alcance ou da duração de um determinado gênero narrativo, mas antes um apontamento para uma crise da percepção ao nível da experiência em geral e não apenas poética. Uma análise mais aprofundada desse problema pode ser encontrada no texto Sob o signo de satã: configurações do tempo e da experiência na modernidade de Benjamin e Baudelaire (Pereira, 2010). materialidade. Como função poética de linguagem (em geral e não apenas gestual), ele "põe em evidência o lado material dos signos; enfatiza as particularidades sensíveis da mensagem" (Galard, 2008, p. 26). Sua eficácia deve-se, em certa medida, ao reconhecimento, por contraste, do ato ou da ação pura. O gesto, diz Galard (idem, p. 27), "é a poesia do ato". No conjunto dos usos corporais, o gesto apresenta-se, então, como ato estético.

\section{IV}

De acordo com Baldine Saint Girons (2008, p. 20 21), o ato estético designa uma forma de conhecimento sensível que instaura uma posição de ação - observadora e crítica; compreende uma espécie de sensibilidade atuante, não apenas receptiva, mas fundamentalmente produtora de sentidos. Nesse esquema, $\mathrm{o}$ ato estético cumpre uma função de integração, orienta-se pela recuperação tanto de um suposto laço substancial (leia-se concreto, material, sensível) entre os indivíduos, quanto da relação entre o sensível e o cognitivo. Essa notação conceitual de ato estético aproxima-o por certo da noção de compartilhamento de sentido ou partilha do sensível de Jacques Rancière. Para Rancière (2000, p. 12), uma "partilha do sensível fixa [...] um comum partilhado e suas partes exclusivas". Como "sistema de evidências sensíveis", a partilha do sensivel revela, "ao mesmo tempo, a existência de um comum e de seus recortes que nele definem lugares e partes respectivas" (Rancière, 2000, p. 12). A partilha do sensivel constitui, portanto, um regime de identificação (visibilidade) de práticas e lugares e modos de ser no espaço do comum - espaço no qual concorre a delimitação do sentido da ação ante as condições de seu aparecimento, efeito e finalidade - isto é, a partir do modo pelo qual a ação se faz sentir, notar.

Porquanto seja o ato estético uma ação deliberada, genuinamente poética, de reconstituição pela sensibilidade das significações latentes ou manifestas da/pela experiência - por força de sua representação na linguagem -, pode-se afirmar que ele se enleia a este regime de visibilidade da ação, que identifica a 
partilha do sensivel propalada por Rancière, sobretudo porque político. Por político entendemos o domínio do comum, do diverso; a esfera do plural; espaço coletivo no qual participam as singularidades, as diferenças, o outro, enfim (Arendt, 2005).

Embora diga respeito a uma operação poética, e nisso se assemelha a um ato discursivo ou um ato artístico, o ato estético desses difere. A rigor, o ato estético não constitui, em sentido estrito, uma linguagem - que identifica, como sabemos, uma prática discursiva ou de arte. Essa definição de ato estético poderia obviamente se contrapor ao sentido do gesto que aqui se esboça, não fosse uma compreensão mais abrangente do termo, mais elástica e menos aplicada, não tributária de uma tradição paralinguística corporal - tomado como o conjunto de signos, de índices, de emblemas que supostamente denunciariam, porque códices, uma dada conduta, um dado comportamento. Em relação a esse aspecto, a psicologia parece apresentar-se como um dos campos mais profícuos de investigação do caráter estrutural e, portanto, sintomático do gesto. Com efeito, é nela que vinga, por exemplo, uma noção de gesto - expressões faciais, formas de vocalização e outros atos corporais involuntários - balizada por critérios fisionômicos, a partir da análise de indícios corporais que marcam, que denunciam traços distintivos de personalidade (Ekman \& Friesen, 2003; Morris, 1996; Trinta, 1985, 1990; Davis, 1979).

$\mathrm{O}$ ato estético remonta, na verdade, a uma forma de ação de catalisação do sentido da experiência: ele torna a experiência cotidiana, em função de um anelo representativo, suscetível à experiência estética; retém da experiência cotidiana a força poética que reside nela (Girons, 2008, p. 44). No plano da especulação de Baldine Saint Girons, isso significa dizer que, no interior do ato estético, se sucedem quatro tempos: um momento de provocação estética, a partir da qual seríamos como que interpelados pelo mundo; um momento de reconhecimento estético: na medida em que identificaríamos o mundo como uma alteridade e, nessa equação, a si como um outro - que ao outro responde, necessariamente, porque assim o percebe, porque é provocado por ele; um momento de eferves- cência, em que se cria, se condensa e se reitera, em função do momento posterior, um vinculum substantiale, o laço, o liame que une o outro a si mesmo e o sensível ao inteligível; e, por fim, o momento no qual culmina a ação estética propriamente dita, o momento da produção, em que a resposta do si mesmo à provocação do outro (em geral, objetivo e do outro de si, subjetivo) produziu com aquele um comum, passível, então, de ser comunicado ou estabelecer comunicação (idem, ibidem).

Tal caracterização de ato estético permite, amiúde, afirmar que este remonta a um modo específico intencional, porém, não necessariamente formalizado -, de captação (que absorve) e reapresentação (que reflete) da experiência cotidiana diante dos efeitos de uma experiência estética. Em outras palavras, o ato estético enseja redimensionar pela ação o espectro de efeitos dela, efeitos por intermédio dos quais se possa estabelecer uma margem maior de alcance do sentido - seja ele dado e/ou produzido.

\section{V}

Essa ampliação da margem de alcance do sentido parece, ademais, aduzir não apenas aos efeitos propriamente ditos da experiência estética, mas, de igual modo, aos conteúdos, objetos e condições dela. Vejamos.

A afirmação de uma experiência como estética indica uma diferença de caráter qualitativo, ao menos desta, da experiência estética, em relação à experiência cotidiana ou em geral. Tal mutação qualitativa da experiência, como nos indica de maneira muito pontual Hans Ulrich Gumbrecht (2006, p. 51), decorre, não raro, de mudanças relativas aos moldes situacionais por intermédio dos quais perguntamos, abordamos os objetos, os eventos, os sujeitos, de uma maneira geral.

A experiência estética designa, nesse entendimento, uma "interrupção inesperada no fluxo do cotidiano" (idem, p. 55), uma experiência extracotidiana, não necessariamente prazerosa, porquanto sensível; é experiência que não encerra em si mesma; que catapulta o pensamento, via sensibilidade, a um outro nível de 
compreensão, de entendimento; opera como forma de captação do sentido que filtra o dado (a sensação) e o significado. Exprime-se como o sentimento, como a sensação de algo "que excede as dimensões e os conceitos que utilizamos normalmente para enfrentar o mundo" (idem, p. 52). A noção de experiência estética - sugerida por Gumbrecht - como que condicionada pela definição de um frame, de uma moldura, de uma circunstância, como forma de enquadramento de ações, como um recorte de tempo e espaço que delimita um comum - para recobrarmos as significações de partilha do sensivel antes mencionadas - permite compreender o gesto como um ato (estético) por intermédio do qual tal experiência pode manifestar-se. No plano da investigação estético-conceitual de Gumbrecht, é a partir da noção de frame que se podem definir os conteúdos, os objetos, as condições e os efeitos da experiência estética.

De acordo com Gumbrecht, os conteúdos da experiência estética compreendem "os sentimentos íntimos, as impressões e as imagens produzidas pela nossa consciência - enquanto inacessíveis aos nossos mundos historicamente específicos", que se nos apresentam como epifânicos; os objetos da experiência estética remontariam, então, "às coisas suscetíveis de desencadear tais sentimentos, impressões e imagens, ao passo que as condições da experiência estética poderiam ser caracterizadas pelas "circunstâncias situacionais historicamente específicas nas quais [essa mesma experiência] estaria baseada"; com efeito, o desinteresse e o prazer desinteressado constituem para Gumbrecht - que retira de Immanuel Kant tais conceitos - noções exemplares que aduzem a um modo de se colocar do sujeito perante o mundo, os acontecimentos, os objetos, os outros sujeitos etc., que propiciam a emergência de tal experiência, uma vez que não se orientariam por nenhum propósito de ordem prática. ${ }^{3}$ Os efeitos da experiência estética

3 As noções de favor e desinteresse (prazer desinteressado) remontam em Kant (2002) ao livre jogo entre a imaginação e o entendimento - o qual caracteriza, para o filósofo em questão, a experiência estética propriamente dita. Tal jogo, contudo, é con- designam, por fim, "as consequências e as transformações decorrentes" dessa espécie de experiência (Gumbrecht, 2006, p. 54).

\section{VI}

Como pudemos observar, o ato estético refere, em função de seus fins, a produção e a subsunção de uma dada experiência, a experiência estética. $\mathrm{O}$ ato estético recobra, pelo efeito, no espaço do comum, o espaço do próprio e vice-versa; é ação que incide necessariamente sobre o real, cuja efetividade se traduz numa compreensão mais apurada, mais profunda e mais complexa, multifacetada, da realidade; que nos convoca a pensar sobre o diverso, o possível, o imponderável. Como ação tributária e ao mesmo tempo produtora de experiência estética, $\mathrm{o}$ ato estético procura amplificar o espaço do singular na própria coletividade, na própria pluralidade dos entes, das coisas, dos sujeitos. Ele reafirma pelo estético o político - na experiência e como experiência.

O gesto, nesse sentido, apresenta-se como a insígnia de uma ação voltada para a afirmação dessa ideia de margem absorvente e em contínua expansão, que enlaça o fora ao dentro e vice-versa; margem na qual se incluem a pluralidade dos sujeitos e do conhecimento; que integra o singular, o próprio ao comum, sem necessariamente subsumi-lo; antes, pelo contrário, que acolhe esse próprio na inteireza de sua diferença. A compreensão do gesto como ato estético parece, assim, antes indicar um pendor de exposição

dicionado pelo estabelecimento de uma dupla atitude do sujeito perante os objetos, qual seja: o favor - que consiste num "deixar o objeto apresentar-se livre à atenção do sujeito", como possibilidade de contemplação do objeto na medida do seu favor - e o desinteresse - como forma de livrar o objeto de fins a ele exteriores. Esse esquema conceitual permite, não obstante, reter um sentido altamente ético do elemento estético, presente na experiência. Tal ideia é desenvolvida - considerando-se o campo da educação e, mais precisamente, o processo de ensino-aprendizagem e a prática docente - no texto Transformação do olhar e compartilhamento do sentido no cinema e na educação (Pereira, 2008). 
e, por conseguinte, de reconhecimento, pelo sensível, de uma alteridade que apenas um recurso de enunciação meramente expressivo - de ênfase, adaptação ou ilustração no corpo de um significado qualquer.

$\mathrm{O}$ gesto articula como ato estético um conjunto de intrassignos; integrado ao corpo o gesto fala ao corpo como corpo. Há, contudo, no corpo algo que transborda a interpretação, que se manifesta na experiência (estética) como presença (material, concreta, objetiva). A dimensão performativa do gesto refere, assim, o processo de globalização desses sentidos, de significação plena e flutuante.

O corpo, diz Zumthor (2007, p. 75-78), é o que dá a medida do mundo. É pelo corpo que o sentido é percebido; ele é o ponto de partida, a origem e o referente do discurso. Ele é a materialização daquilo que é próprio ao indivíduo, realidade vivida que determina a relação deste com o mundo. "Dotado de uma significação incomparável, ele existe à imagem de meu ser: é ele que eu vivo, possuo e sou, para o melhor e para o pior" (idem, p. 23).

A concepção de corpo por Zumthor apresentada encontra-se, como se pode observar, balizada pela discussão em torno do sentido da performance na experiência da leitura do texto, em especial do texto poético, literário. Também Zumthor está preocupado com a eficácia da comunicação, todavia, seu enfoque dirige-se às vicissitudes e potencialidades do texto escrito em performance. Dito de outro modo, o autor indaga sobre as condições que possibilitam recobrar um sentido integral do algo apresentado em texto; pergunta sobre as condições de emergência de uma atmosfera afetiva, por intermédio da qual pode ser captada uma sorte de sentidos que não se reduz ou sequer pode ser reduzida a signo.

A performance, nesse sentido, constitui uma forma-força, pela qual tal experiência de texto e conhecimento - portado pelo texto - pode manifestar-se, ser comunicada; isso porque, como meio de comunicação periférico e concreto, a performance modifica o conhecimento; "comunicando, ela o marca" (idem, p. 32).

No entendimento de Paul Zumthor, o ato de comunicar, abrangido pela ideia de performance, "não consiste somente em fazer passar uma informação; [comunicar] é tentar mudar aquele a quem se dirige; receber uma comunicação é necessariamente sofrer uma transformação". Ora, ele enfatiza, "quando se toca no essencial [...] nenhuma mudança pode deixar de ser concernente ao conjunto da sensorialidade do homem" (idem, p. 52). Isso explica porque nesse esquema a performance adquire um duplo status: ela é uma forma-força de expressão, ao mesmo tempo que um momento da recepção, "o momento em que um enunciado é realmente recebido" (idem, p. 50), conformando um ato de comunicação - como prática dinâmica de trocas simbólicas, imaginárias e reais.

Termo antropológico e não histórico, relativo, por um lado, às condições de expressão, e da percepção, por outro, performance designa um ato de comunicação como tal; refere-se a um momento tomado como presente. A palavra significa a presença concreta de participantes implicados nesse ato de maneira imediata. Nesse sentido, não é falso dizer que a performance existe fora da duração. Ela atualiza virtualidades mais ou menos numerosas, sentidas com maior ou menor clareza. Ela as faz "passar ao ato", fora de toda consideração pelo tempo. Por isso mesmo, a performance é a única que realiza aquilo que os autores alemães, a propósito da recepção, chamam de "concretização". (idem, p. 50, grifos do original)

\section{VII}

A despeito da especificidade do problema, as intuições de Zumthor concernentes aos significados de corpo, de experiência estética, de performance [performatividade] parecem adequar-se de maneira muito própria aos termos de um novo equacionamento conceitual que, neste estudo, se desdobra em vista da relação entre gesto, experiência estética e prática docente. Elas remetem, invariavelmente, a meios de portabilidade e comunicação de sentidos; respondem à capacidade de estabelecer um espaço comum, de contato, um ponto de convergência real, concreto, entre a experiência e o pensamento, entre o outro e o si mesmo. 
Contra a economia dos sentidos, contra a primazia do conhecimento formal sobre o sensível, contra a incompatibilidade do discurso em relação ao real da ação, contra o comedimento, a brandura e o alinhamento, contra a etiqueta e o automatismo das condutas moldadas pelos interesses de uma determinada classe econômica e social é que se dirige o presente estudo.

A compreensão de algo tão ínfimo, tão insólito quanto o gesto na prática docente, poderia parecer despropositada, caso não se orientasse, não fosse mobilizada pela necessidade de reconstrução do plural no espaço do comum. É no corpo, “como realidade vivida, que determina minha relação com o mundo; [...] como o conjunto de tecidos e órgãos, suporte da vida psíquica, [que sofre] as pressões do social, do institucional, do jurídico" (idem, p. 23), que se instaura um campo de imantação de sentidos, de forças e de tensões, em que se encenam dramas reais.

A educação como produto de uma cultura e, ao mesmo tempo, dispositivo de manutenção da cultura, coopera para o contorno não só de um modus vivendi, como também da contenção/formalização de um corpo que nele e dele participa. Se o corpo constitui, como vimos, um território problemático, porque atravessado pelo desejo, é sobre ele que incide, primeiro, a lâmina ácida e fria da razão discursiva que cinde o sujeito do mundo ao qual pertence, da materialidade que o conforma, que o constitui.

O exame da dimensão performativa do gesto permite, assim, tomar consciência das potencialidades do corpo no processo de ensino-aprendizagem; diz respeito, na verdade, mais à formação de um sujeito atento, de olhar atento, que precisamente o mero embelezamento das ações físicas, de tentar estabelecer pela contenção, pela rigidez ou afetação, uma relação de domínio no processo interativo do conhecimento; consiste também na emissão de um ruído que permita ressoar outros modos, outras configurações de ser no tecido social.

A proposição de uma educação pautada pelo reconhecimento do gesto como ato estético - como disparador de uma experiência de conhecimento mais plena, mais concreta - passa, nesse sentido, pelo crivo de uma razão mais elástica, a estética. Com efeito, o estudo feito até aqui procurou ressaltar as qualidades poéticas do gesto em detrimento da apresentação de seus códigos, de seu modo de operação aplicado. Essa opção argumentativa ressalta, na verdade, a restrição à adoção de um sentido de gesto instrumental, mecânico. Isso quer dizer, ao fim e ao cabo, que pensar a prática docente do ponto de vista do gesto e da dimensão aqui elencada, a performativa opera como um modo de captar e ressignificar esse suporte a partir do qual tudo se constrói enfim.

A dimensão performativa do gesto na prática docente responde ao imperativo de uma docência ética, política, visto que reintegra o corpo - que constitui um próprio, um singular - no social - espaço do plural, na relação mesma com a experiência. A tarefa de ensinar e aprender não seria então aquela de fazer construir em si os gestos significativos produzidos pelo outro e para o outro? Não seria esse o desafio de uma educação que intui, que enseja ser atual? Para isso, concorre a ação estética presente no gesto.

\section{Referências bibliográficas}

ARENDT, Hannah. A condição humana. Tradução de Roberto Raposo. Posfácio de Celso Lafer. Rio de Janeiro: Forense Universitária, 2005.

BENJAMIN, Walter. Sobre alguns temas em Baudelaire. Obras Escolhidas III. In: Charles Baudelaire: um lírico na era do capitalismo tardio. São Paulo: Brasiliense, 1989. . O narrador: considerações sobre a obra de Nicolai Leskov. In: BENJAMIN, Walter. Magia e técnica, arte e politica. Obras Escolhidas I. Tradução de Sergio Paulo Rouanet. Prefácio de Jeanne-Marie Gagnebin. São Paulo: Brasiliense, 1994.

DAVIS, Flora. A comunicação não verbal. São Paulo: Summus, 1979.

EKMAN, Paul; FRIESE, Wallace. Unmasking the face: a guide to recognizing emotions from facial expressions. Cambridge: Malor Books, 2003.

GALARD, Jean. A beleza do gesto: uma estética das condutas. Tradução de Mary Amazonas Leite de Barros. São Paulo: Editora da Universidade de São Paulo, 2008. 
GIRONS, Baldine Saint. L'acte esthetique : cinq reels, cinq risques de se perdre. Paris: Klincksieck, 2008.

GUMBRECHT, Hans Ulrich. A modernização dos sentidos. Tradução de Lawrence Flores Pereira. São Paulo: Editora 34, 1998.

Pequenas crises: experiência estética nos mundos coti-

dianos. In: GUIMARÃES, Cesar; LEAL, Bruno Souza; MEN-

DONÇA, Carlos (Org.). Comunicação e experiência estética. Belo

Horizonte: Editora UFMG, 2006.

HOUAISS. Dicionário de Língua Portuguesa. Rio de Janeiro: Editora Objetiva, 2003.

JOUSSE, Marcel. L'Anthropologie du Geste. Paris: Gallimard, 2008 .

KANT, Immanuel. Crítica da Faculdade do Juízo. Tradução de Valerio Rohden e Antônio Marques. Rio de Janeiro: Forense Universitária, 2002.

LEROI-GOURHAN, André. Le geste et la parole: technique et langage. Paris: Éditions Albin Michel, 2008.

LINS, Osman. Os gestos. In: Osman Lins: os melhores contos. Seleção e prefácio de Sandra Nitrini. São Paulo: Global, 2003. p. 31-38.

MORRIS, Desmond. A linguagem do corpo. Lisboa: Gradiva, 1996.

PEREIRA, Marcelo de Andrade. Sob o signo de satã: configurações do tempo e da experiência na modernidade de Benjamin e Baudelaire. Trama Interdisciplinar, n. 1, v. 1, p. 99-112, jan./ jun. 2010.

Transformação do olhar e compartilhamento do sentido no cinema e na educação. Educação \& Realidade, n. 33, v. 1, p. 169-180, jan./jun. 2008.

RANCIÈRE, Jacques. Le partage du sensible: esthetique et politique. Paris: La Fabrique Editions, 2000.

SANTOS, Fausto dos. Estética máxima. Chapecó: Argos, 2003.

TRINTA, Aluizio Ramos. Comunicação do corpo. São Paulo: Editora Ática, 1990.

ZUMTHOR, Paul. Performance, recepção, leitura. Tradução de Jerusa Pires Ferreira e Suely Fenerich. São Paulo: Cosac Naify, 2007.

MARCELO DEANDRADE PEREIRA, Doutor em educação pela UFRGS. Professor adjunto do Departamento de Fundamentos da Educação da UFSM. Coordenador do Núcleo de Estudos em Estética e Educação (FLOEMA) da UFSM. Membro do Grupo de Estudos em Educação, Teatro e Performance (GETEPE) da UFRGS. Publicou recentemente: Pedagogia da performance: do uso poético da palavra na prática educativa (Educação \& Realidade, n. 35, v. 2, maio/ago. 2010); Juventude, experiência e conhecimento em Walter Benjamin: para um novo saber da educação (Currículo sem Fronteiras, n. 2, v. 9, p. 242-257, jul./dez. 2009). Pesquisa em andamento: "Performance e educação: interfaces, conceitos e prática docente" (pesquisa financiada pelo CNPq). E-mail: doutorfungo@gmail.com

Recebido em agosto de 2010 Aprovado em outubro de 2010 
Marcelo de Andrade Pereira

\section{A dimensão performativa do gesto na prática docente}

O presente estudo, de caráter ensaístico, discorre, desde um ponto de vista filosófico, sobre o sentido do gesto em geral e na prática educativa. A análise procede da diferenciação do sentido do gesto - do mero gesto motor em relação aos gestos figurado ou expressivo - a partir da qual se depreende a acepção própria de gesto à investigação. Infere-se que a dimensão performativa e, portanto, expressiva do gesto permite criar um espaço de experimentação e construção do saber qualitativamente distinto do ordinário, não regulado por fins de ordem meramente biológica, cognitiva ou instrumental. Essa perspectiva compreende o gesto desde sua dimensão performativa como ato estético. Descrevem-se e analisam-se os conteúdos, os objetos, as condições e os efeitos do elemento estético em face de uma prática docente performativa. A investigação é amparada pelas intuições de Osman Lins, Walter Benjamin, Hans Ulrich Gumbrecht, Jean Galard, Baldine Saint Girons, entre outros.

Palavras-chave: educação estética, comunicação, prática docente, gesto, performance
The performative dimension of gesture in teaching practice

The present study, in the form of an essay, argues, from a philosophical point of view, about the meaning of gestures in general and in teaching practice. The analysis proceeds from the differentiation of the meaning of the gesture - from a mere motor gesture to symbolic or expressive gestures - from which one perceives the proper meaning of gesture for this investigation. It is inferred that the performative, and therefore expressive, dimension of the gesture allows for the creation of a space for experimentation and construction of knowledge that is qualitatively distinct from the ordinary and not regulated by merely biological, cognitive or instrumental purposes. This perspective comprehends gesture from its performative dimension as an aesthetic act. The study describes and analyzes the contents, the objects, the conditions and the effects of the aesthetic element with regard to a performative teaching practice. The investigation is supported by the intuitions of Osman Lins, Walter Benjamin, Hans Ulrich Gumbrecht, Jean Galard, Baldine Saint Girons, among others.

Key words: aesthetic education, communication, teaching practice, gesture, performance

\section{La dimensión preformativa del} gesto en la práctica docente

Este artículo, de carácter ensayístico, discurre, desde un punto de vista filosófico, sobre el sentido del gesto en forma general y en la práctica de la educación. El análisis procede de la diferenciación del sentido del gesto - del simple gesto motor en relación a los gestos figurados o expresivos - a partir de lo cual se desprende la acepción propia del gesto a la investigación. Se deduce que la dimensión del desempeño $y$, por lo tanto, expresiva del gesto, permite crear un espacio de experimentación y construcción del saber cualitativamente diferente del ordinario, no regulado por intenciones de orden puramente biológica, cognitiva o instrumental. Esta perspectiva comprende el gesto desde su dimensión de desempeño como un acto estético. Se describen y se analizan los contenidos, los objetos, las condiciones y los efectos del elemento estético en razón de una práctica docente de desempeño. La investigacipon es amparada por las intuiciones de Osman Lins, Walter Benjamin, Hans Ulrich Gumbrecht, Jean Galard, Baldine Saint Girons, entre otros.

Palabras clave: educación estética, comunicación, práctica docente, gesto, desempeño 